\title{
Sobre a formação do professor alfabetizador: contributos para a caracterização do conhecimento de base do professor alfabetizador
}

Íris Susana Pires Pereira*

Fernanda Leopoldina Viana**

Cristina Vieira da Silva***

\section{Resumo}

Neste texto recuperamos o quadro teórico proposto por Lee S. Shulman para dar resposta à seguinte questão: Qual o conhecimento de base do professor alfabetizador? A partir desta questão, entende-se que o ensino da alfabetização implica a convocação e a operacionalização de conhecimentos de diferentes naturezas, alguns dos quais subinvestigados e, por isso mesmo, ainda dependentes das intuiçóes e práticas não sistematizadas e dificilmente passíveis de aprendizagem nos contextos de formação académica. Argumenta-se que é pela mesma ordem de razóes que a tarefa pedagógica de ensinar a ler se torna difícil de conceber para os jovens professores. Defende-se que o modelo do conhecimento do professor alfabetizador que apresentamos se configura como basilar na concepção da formação do professor alfabetizador no atual contexto formativo português, que também é brevemente caracterizado.

Palavras-chave: Professor alfabetizador. Formação profissional. Professores de educação básica.

\footnotetext{
* Doutora em Estudos da Criança pela Universidade do Minho, Portugal. Professora do Instituto de Educaçáo da Universidade do Minho, Portugal. Durante a realização deste trabalho, a autora beneficiou-se de uma Bolsa de Licença Sabática (SFRH/BSAB/1440/2014), atribuída pela Fundação para a Ciência e a Tecnologia (FCT), Portugal.

** Doutora em Psicologia pela Universidade do Minho, Portugal. Professora do Instituto de Estudos da Criança da Universidade do Minho, Portugal.

*** Doutora em Linguística pela Universidade Nova de Lisboa, Portugal. Professora do Departamento de Formaçáo em Educação Básica da Escola Superior de Educação de Paula Frassinetti, em Porto, Portugal.
} 


\section{Introdução}

O ensino da alfabetização constitui uma tarefa pedagógica complexa. Esta é, por exemplo, a opiniáo de António Nóvoa (1995, p. 78), que afirma que "mais do que os vários outros tipos de professores, os alfabetizadores precisam de uma formação especial, mais sólida e sofisticada, dada a importância e a complexidade de seu trabalho". Os futuros professores dão um forte indício dessa complexidade quando confessam abertamente o seu enorme receio de enfrentar a experiência de ensinar as crianças do $1^{\circ}$ ano a ler. Nesse âmbito, diferentemente do que parece acontecer noutros âmbitos do ensino das séries iniciais a propósito dos quais os professores em formação têm (muito frequentemente) perceçôes (demasiado) positivas (BALL, 1990), as memórias e representaçóes das experiências pessoais dos futuros professores (TARDIF, 2002) enquanto aprendizes de leitores parecem, pois, estar longe de ser suficientes para ajudá-los a conceber a realização desta tarefa pedagógica.

Neste texto recuperamos ideias de Lee S. Shulman (1986) sobre o conhecimento do professor para expormos o nosso entendimento das razóes da dificuldade que o processo de alfabetização coloca aos professores em formação. $\mathrm{O}$ autor identificou, na diversidade do conhecimento do professor, a origem da sua especialização, mas também a origem da complexidade do seu trabalho prático face ao de outros profissionais. O seu modelo tem sido legitimado pela exploração da definição do conhecimento de base de professores de diversas áreas (nomeadamente matemática e ciências). É nossa convicção que este modelo também se configura como um instrumento teórico importante na definição do conhecimento de base do professor alfabetizador.

Dessa forma, o quadro teórico de Shulman (1986) é explorado à procura da resposta à seguinte questão: Qual o conhecimento de base do professor alfabetizador? A nossa resposta é a de que o ensino da alfabetização implica a convocação e operacionalização de conhecimentos de diferentes naturezas, alguns dos quais subinvestigados e, por isso mesmo, ainda dependentes das intuições e práticas não sistematizadas e dificilmente passíveis de aprendizagem nos contextos de formação académica. A nosso ver, é pela mesma ordem de razóes que a tarefa pedagógica de ensinar a ler se torna difícil de imaginar para os jovens professores.

A conceptualização do conhecimento de base do professor alfabetizador que propomos é também sustentada na nossa experiência profissional de 
formação inicial e continuada de professores alfabetizadores em Portugal, refletindo, dessa forma, um quadro legal e um panorama formativo diferente do Brasil. É, contudo, nossa convicção que o potencial da síntese que propomos será igualmente relevante nos contextos de formação de professores alfabetizadores portugueses e brasileiros e poderá iluminar potencialidades e necessidades formativas e investigativas em ambos os contextos.

O texto começa por apresentar brevemente o atual contexto português de formação do professor alfabetizador. Introduzimos e discutimos depois o modelo do conhecimento do professor de Shulman (1986, 1987), para, em seguida, apresentarmos um modelo de conhecimento do professor alfabetizador. $\mathrm{O}$ texto conclui com a formulaçáo da nossa resposta à pergunta central que conduz este ensaio e com a formulação de percursos investigativos prementes relativamente à formação do professor alfabetizador em Portugal.

\section{O contexto português de formação de professores}

$\mathrm{O}$ atual contexto formativo do professor alfabetizador em Portugal decorre de uma evoluçáo que, nos últimos 30 anos, implicou profundas alteraçôes estruturais na formação de professores do $1^{\circ}$ Ciclo do Ensino Básico (professores generalistas responsáveis pela aprendizagem formal da Leitura e da Escrita de crianças entre os cinco/seis e os nove anos).

A formação inicial desses profissionais correspondeu, até meados da década de 80, a uma formação pós-secundária de nível médio,

[...] caracterizada pelo enfoque no treino de metodologias de ensino das matérias escolares que integravam o currículo do ensino primário, com práticas de ensino supervisionado em escolas escolhidas para o efeito e em que não era valorizado o conhecimento teórico enraizado na investigaçáo científica (SIM-SIM, 2001, p. 21).

Procurando dar resposta a esta situação, surgem, nesta mesma época, as Escolas Superiores de Educação (ESE) e os Centros Integrados de Formação de Professores (CIFOP), naquilo que constitui um passo decisivo em termos de qualificação académica desses profissionais. Tal esforço de qualificação viria a conduzir à obrigatoriedade do grau de licenciatura na formação dos docentes portugueses de todos os níveis de ensino não superior, naquela que foi uma 
oportunidade de atualização e consolidação de conhecimentos e de reflexão para muitos professores.

Ainda que a alocação desta formação ao nível do Ensino Superior tenha contribuído para uma nova forma de encarar a profissionalização desses docentes, ela não significou, por si só, uma garantia de qualidade. No que se refere especificamente à formação para o ensino da língua portuguesa no $1^{\circ}$ Ciclo do Ensino Básico, uma publicaçáo de 2001, da responsabilidade do Instituto Nacional de Acreditação da Formação de Professores (INAFOP), dá conta de um conjunto de debilidades a vários níveis (SIM-SIM, 2001): nos formandos, uma desvalorização da informaçáo teórica em detrimento de um excessivo "endeusamento" da componente prática; nos formadores, alguma dificuldade de articulação teoria/prática; nos cursos, grande oscilação quanto ao peso atribuído à formaçáo para o ensino da leitura, conteúdos desatualizados e desajustados face aos resultados da investigação na área, entre outros. De facto, a formação dos professores do $1^{\circ}$ Ciclo passou a ser, na esmagadora maioria dos cursos, englobada em "variantes" que habilitavam para o ensino generalista (licenciatura em Ensino do $1^{\circ}$ Ciclo do Ensino Básico) e, noutros cursos, também para o ensino específico no $2^{\circ}$ Ciclo na variante escolhida (ex: Ensino da Educação Física, Música, Matemática etc.). Os planos curriculares da maior parte desses cursos náo incluíam sequer unidades curriculares ou conteúdos relativos à didática da leitura (VIANA, 2006).

A criação do INAFOP, em 1998, visava justamente implementar um sistema que, em matéria de regulação da formação desses profissionais, permitisse garantir a adequaçáo dos cursos de formação de professores (públicos e privados), nomeadamente quanto a sua qualidade e condiçóes de funcionamento e as exigências do desempenho docente nas escolas.

Nesse mesmo ano, foram publicados os perfis gerais (PORTUGAL, 2001a) e específicos (PORTUGAL, 2001b) de desempenho do educador de infância e dos professores do Ensino Básico (no qual se inclui o $1^{\circ}$ Ciclo), perfis esses que, apesar da extinção do INAFOP, mantêm-se até hoje como referenciais válidos, tendo sido contemplados no regime jurídico da habilitação profissional para a docência de educadores e professores (PORTUGAL, 2007).

Dez anos passados sobre o estabelecimento da exigência da licenciatura como habilitaçáo mínima para a docência, a publicação do Decreto-Lei no 43, de 22 de fevereiro 2007 (PORTUGAL, 2007), veio, na sequência do designado Processo de Bolonha (que pretende harmonizar um espaço europeu de ensino 
superior), aprovar o regime jurídico de habilitação profissional para a docência na Educação Pré-Escolar e nos Ensinos Básico e Secundário, estruturando a formaçáo dos professores em dois ciclos distintos e estabelecendo que o mestrado passa a ser o grau mínimo de qualificação para acesso à carreira docente: um primeiro ciclo de formação (licenciatura em Educaçáo Básica, com 3 anos de duração), que incide essencialmente sobre as áreas científicas específicas de cada domínio de habilitação para a docência, e um segundo ciclo de formação (mestrado em Ensino do $1^{\circ}$ Ciclo do Ensino Básico, do Pré-Escolar e do $1^{\circ}$ Ciclo ou do $1^{\circ}$ e $2^{\circ}$ Ciclos do Ensino Básico), conferindo habilitaçáo profissional, que contempla sobretudo as didáticas específicas, a formação educacional geral e a prática pedagógica supervisionada.

A determinação, por parte da tutela, de que o acesso à profissão docente passe a implicar um número mínimo de créditos (ECTS) na(s) área(s) de docência nos níveis e ciclos de ensino abrangidos veio exigir às instituiçóes uma maior atençáo para a necessidade de valorizar a componente do conhecimento disciplinar, mediante a oferta de uma sólida formação nas diversas áreas científicas que integram o respetivo currículo - nomeadamente na área da língua portuguesa, com um peso de 30 créditos na Formação da Área de Docência (FAD), a par da Matemática, do Estudo do Meio e das Expressóes.

Já no ano de 2014, mediante novo regime jurídico da habilitação profissional para a docência na Educação Pré-Escolar e nos Ensinos Básico e Secundário (PORTUGAL, 2014), a duração dos cursos de mestrado é alargada: no caso do mestrado em Educação Pré-Escolar e Ensino do $1^{\circ}$ Ciclo do Ensino Básico é aumentado de 3 para 4 semestres, a mesma duração que já havia sido fixada para o mestrado em Ensino do $1^{\circ}$ e do $2^{\circ}$ Ciclo do Ensino Básico.

Ainda que fortemente condicionado pelo atual enquadramento jurídico que define as habilitaçóes dos professores, é premente estabelecer o perfil específico de formação do professor albabetizador. Aliás, esta intenção de profissionalizar a atividade docente está condicionada à definição de um conhecimento de base para o ensino (RAMOS; GRAÇA; NASCIMENTO, 2008), que, no caso do professor de $1^{\circ}$ Ciclo, também inclui a tarefa de alfabetizar. A questão a que procuramos aqui responder consiste, pois, em identificar, atendendo às atuais condicionantes legais, o conhecimento de que não se pode prescindir neste novo perfil formativo de professores alfabetizadores, sustentando esta discussão na nossa experiência profissional de formadoras desses profissionais. 


\section{Conhecimento profissional de professores: o modelo de Lee S. Shulman}

O trabalho de Shulman $(1986,1987)$ foi determinante no reconhecimento da necessidade de codificação do "conhecimento de base" como fundamental na profissionalização do professor. Shulman (1986) partiu da constatação da existência de um "paradigma perdido" no âmbito da formação de professores, referente à falta de conteúdo na investigação sobre o ensino e a atividade dos professores, para cuja "recuperaçâo" contribuiu indelevelmente ao identificar sete categorias de conhecimen to que definem o saber de base desses profissionais, nomeadamente conhecimento: a) do conteúdo; b) pedagógico geral; c) do currículo; d) pedagógico do conteúdo; e) dos alunos; f) do contexto educativo; g) dos objetivos, propósitos e valores educativos e seus fundamentos históricos e filosóficos (SHULMAN, 1987). Para este investigador, é o conhecimento que permite ao professor fazer da sua profissão "the exercise of reasoned judgment rather than the display of correct behaviour" (SHULMAN, 1986, p. 12); é o conhecimento que permite o controlo consciente da sua prática: "The vision I hold of teaching and teacher education is a vision of professionals who are capable not only of acting, but of enacting - of acting in a manner that is self-conscious with respect to what their act is a case of, or to what their act entails"2 (SHULMAN, 1986, p. 13).

Ao recuperar o paradigma perdido, Shulman (1986) não dá, como se constata acima, exclusividade ao conhecimento do conteúdo específico (o que ensinar), afirmando, aliás, que "mere content knowledge is likely to be as useless pedagogically as content-free skill"3 (SHULMAN, 1986, p. 8). Na verdade, entre os vários tipos de conhecimento que elenca, destaca a categoria de conhecimento pedagógico do conteúdo (Pedagogical Content Knowledge, doravante PCK), que diz respeito ao conjunto de conhecimento sobre "como ensinar um conteúdo ou tópico específico", e que, em sua opiniáo, define o conhecimento profissional especializado do professor de cada área específica:

Among these categories, pedagogical content knowledge is of special interest because it identifies the distinctive bodies of knowledge for teaching. It represents the blending of content and pedagogy into an understanding of how particular topics, problems or issues are organized, 
represented, and adapted to the diverse interests and abilities of learners, and presented for instruction. (SHULMAN, 1987, p. 8) $)^{4}$.

Grossman (1990) densifica esta teorização ao redefinir e estruturar o PCK em quatro das categorias de conhecimento inicialmente definidas por Shulman - conhecimento dos propósitos para ensinar, conhecimento da compreensão dos estudantes, conhecimento do currículo e conhecimento das estratégias instrucionais -, bem como ao interrelacionar essas com as outras categorias de conhecimento, que, juntamente com o PCK, intervêm na constituição do conhecimento de base do professor (Figura 1).

Figura 1 - Modelo da estruturaçáo do conhecimento do professor

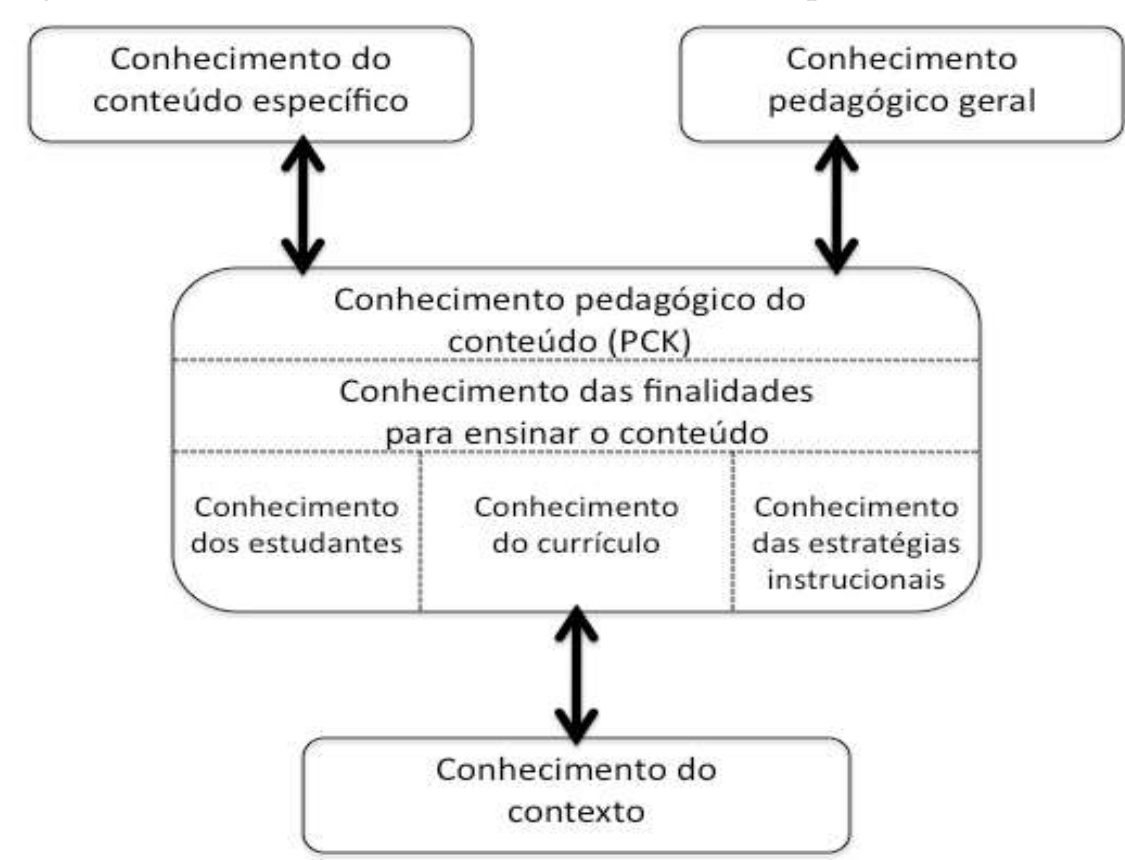

Fonte: Adaptado de Grossman, 1990.

O modelo do conhecimento do professor proposto por Shulman (1986) e desenvolvido por Grossman (1990) tem sido assumido por vários investigadores de diferentes áreas de formação de professores (HILL; BALL; 
SCHILLING, 2008; MAGNUSSON; KRAJICK; BORKO, 1999), que, em muitos casos, o tem ampliado e aprofundado.

Este modelo não deve ser tomado como uma reivindicação exclusiva do papel do conhecimento de tipo "académico" na formação do professor: Shulman $(1986,1987)$ refere que a formação académica e os resultados da investigação são duas das quatro fontes de conhecimento para o ensino, sendo as outras o conhecimento do contexto e materiais e o da própria prática. Como o autor afirma, "comprehension alone is not sufficient. The usefulness of such knowledge lies in its value for judgment and action"5 (SHULMAN, 1987, p. 19). Desse modo, também se percebe que a sua noção de "conhecimento de base" não deve ser tomada como sinónimo de conhecimento prático do professor, sendo este um subproduto da "experiência refletida" (SCHÖN, 1983).

O modelo de Shulman $(1986,1987)$ é, sim, uma codificação dos "complexos fundamentos" da construção do conhecimento profissional, apresentando-se igualmente como ponto de partida para a investigação e definição desse conhecimento, que assim pode ser tornado tangível e disponibilizado para a aprendizagem profissional de professores. É nossa convicção que a exploração deste modelo ganha especial pertinência em contextos formativos como o atualmente existente em Portugal, que, de acordo com o que vimos acima, pode ser assumido como potenciando o desenvolvimento do "conhecimento de base". Foi com essa intençấo que utilizámos este modelo na descriçâo do conhecimento de base do professor alfabetizador, que apresentaremos em seguida.

\section{Conhecimento profissional de professores alfabetizadores: proposta de modelo}

O modelo de Shulman $(1986,1987)$ permite mapear a complexidade intuída por uns e sentida por outros no conhecimento de base do professor alfabetizador. É de facto um conhecimento complexo porque coloca em relação conhecimentos de diferentes áreas: linguística, cognitiva e sociocultural, entre outras. Contudo, ao revelar essa complexidade, o modelo do autor também mostra que há áreas do conhecimento mais investigadas do que outras. O nosso modelo, que descreveremos a seguir no texto, está representado na Figura 2. 
Figura 2 - Modelo da estruturaçáo do conhecimento de base do professor alfabetizador

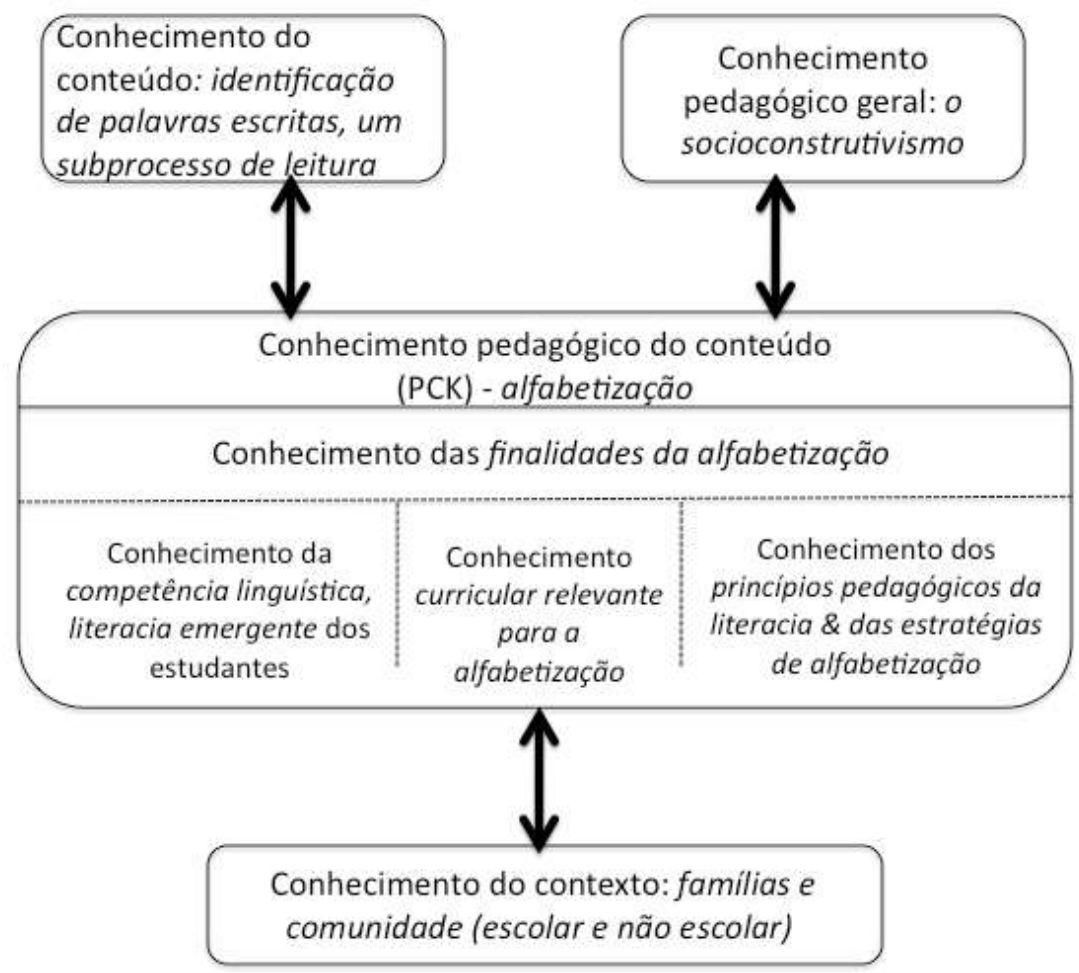

Fonte: Autoras.

\section{Conhecimento do conteúdo específico: identificação de palavras escritas, um subprocesso de leitura}

A compreensão da pedagogia específica da alfabetização é dependente de um entendimento do processo de leitura (de linguagem verbal escrita). Sem esse entendimento, que tem origem tanto em abordagens de natureza cognitivista como sociocultural, pensar a pedagogia da alfabetizaçáo simplesmente náo faz sentido.

Ler é "o processo de simultaneamente extrair e construir significado através da interação e envolvimento com a linguagem escrita" (RAND, 2002, p. 11). Trata-se de um processo complexo que requer o processamento e a 
integração de várias fontes de informação e que permite transformar uma representação de entrada, geralmente visual - ou táctil, no caso de leitura pelo sistema Braille - numa outra representação (de saída), esta de natureza semântica. Ler é, portanto, construir sentido.

A representação visual que nos interessa neste texto é a constituída pelo código alfabético de escrita. No processo de alfabetização, um aspecto importante a ter em mente é o de que esse código é um construto cultural. O professor tem de reconhecê-lo como artefacto desenvolvido para representar a linguagem oral. Precisa, pois, conhecer as unidades e regras (nem sempre coincidentes na leitura e escrita) de representação das unidades sonoras e prosódicas, as convençôes técnicas. Além disso, éfundamental que o professor compreenda que este artefacto adquiriu e adquire sentido no uso múltiplo e multifuncional que dele é socialmente feito nas práticas especializadas de construção de significado, isto é, nas práticas de literacia/letramento (ONG, 2002).

Desse modo, o domínio do código escrito é uma das maiores especificidades da leitura (PEREIRA, 2014). Permite a identificação das palavras escritas (i.e., ter acesso ao seu significado) e, desse modo, libertar recursos para o desencadear dos restantes subprocessos mentais implicados na construção da compreensão de qualquer texto escrito (IRWIN, 2007; GIASSON, 2005). Dificuldades no processo de identificaçáo das palavras escritas comprometem o estabelecimento de relaçōes entre os diversos segmentos textuais (palavras, frases, parágrafos), perturbando a realização de inferências e a construção de uma representação global do texto (BALOTA, 1990; EHRI, 1992; SALLES; PARENTE, 2002, 2004; YUILL; OAKHILL, 1991). No entanto, um bom desempenho ao nível da identificação de palavras escritas não assegura a compreensão do que é lido, sabendo-se hoje que, à semelhança do que se passa com a identificaçáo de palavras escritas, também os restantes processos de compreensão textual exigem um trabalho de ensino intencional.

A identificação das palavras escritas, que neste texto assumimos como a essência do processo de alfabetização, é o processo cognitivo através do qual um indivíduo-leitor associa a forma escrita de uma palavra à representação semântica que dela tem guardada no seu repositório mental (quando essa palavra lhe é oralmente familiar). Convoca um conjunto complexo de processos mentais, como perceção visual, atenção, memória, linguagem, e pode ser realizado por duas vias principais, de acordo com a familiaridade do indivíduo-leitor com a representaçâo escrita das palavras (COLTHEART et al., 1993). 
Assim, perante palavras cuja representação escrita lhe é desconhecida, o leitor tem de tentar uma identificaçáo, sobretudo, auditiva, acedendo à forma fonológica da palavra através da descodificação, e, a partir desse processo de conversão de letras em sons, ao significado da palavra. Neste caso, ativa a via fonológica ou sublexical (também designada de indireta) de identificaçáo de palavras escritas. Por outro lado, perante palavras cuja escrita é familiar, o leitor faz um reconhecimento visual e global, acedendo diretamente à imagem dessa palavra que tem no seu repositório mental e ativando de uma forma praticamente imediata o seu significado. Dessa forma, ativa a via ortográfica ou lexical (ou direta) de identificação de palavras escritas - sabendo-se contudo que, mesmo nesses casos, o leitor ativa mentalmente a forma fonológica da palavra que vê escrita (SIM-SIM, 2009).

\section{Conhecimento pedagógico geral: o socioconstrutivismo}

A compreensão das consideraçóes específicas sobre PCK implicado no processo de alfabetização é igualmente dependente do entendimento de ideias pedagógicas centrais defendidas pelas correntes socioconstrutivistas.

O socioconstrutivismo sustenta-se em três ideias centrais. Uma dessas assunçóes é a de que a criança é um construtor ativo de conhecimento (e não um mero receptor do que o professor tem para ensinar), que traz para qualquer situação pedagógica conhecimentos já construídos, tal como estabelecido por Jean Piaget (cf. DONALDSON, 1984). Uma outra é a de que o professor é um andaime (VYGOTSKY, 1995; BRUNER, 1988) para construção da aprendizagem através da preparação de situaçôes-problema "propostas e dirigidas com a intenção de favorecer a ação do aprendiz sobre determinado objeto de conhecimento, e essa ação está na origem de toda e qualquer aprendizagem" (WEISZ, 2002, p. 65). Segundo Weisz (2002, p. 61), "a construção do conhecimento deve partir de situaçóes nas quais [a criança] possa agir sobre o que é objeto do seu conhecimento, pensar sobre ele, recebendo ajuda, sendo desafiado a refletir, interagindo com outras pessoas". A terceira ideia que estrutura o socioconstrutivismo é a de que, nessas situaçóes pedagógicas, o objeto de aprendizagem deve apresentar-se na sua condição de "objeto sociocultural real, sem se transformar em objeto escolar vazio de significado social" (WEISZ, 2002, p. 66). É a dinâmica desta tríade circunstancial que favorece a criação das Zonas de Desenvolvimento Próximo (VYGOTSKY, 1995), no âmbito das quais a aprendizagem se configura. 
De acordo com estas ideias, que se ergueram em oposição a abordagens pedagógicas tradicionais, o processo de ensino, realizado pelo professor, subjugase ao processo de aprendizagem, realizado pela criança, ou seja, "não é o processo de aprendizagem que se deve adaptar ao de ensino, mas o processo de ensino é que se tem de adaptar ao de aprendizagem" (WEISZ, 2002, p. 65). Como diz a autora, "o processo de ensino deve dialogar com o de aprendizagem" (WEISZ, 2002, p. 65). Esta abordagem pedagógica subjaz a todo o PCK implicado no ensino da alfabetização, a seguir apresentado.

\section{Conhecimento Pedagógico do Conteúdo (PCK) para a alfabetização}

\section{Conhecimento das finalidades da alfabetização}

A principal finalidade da alfabetização é a de tornar os estudantes autónomos no processo de identificação das palavras escritas (SIM-SIM, 2009). Esta autonomia implica automaticidade no reconhecimento das palavras escritas (i.e., o seu processamento a um nível inconsciente e sem custos cognitivos, ou seja, sem esforço) e autorregulação do processo (i.e., o seu controlo ativo por parte do leitor). $\mathrm{O}$ acesso ao significado das unidades (= palavras) escritas que assim se torna possível habilita as operaçóes mentais necessárias à compreensão profunda e elaborada de um texto. A alfabetização configura-se assim como a construção da porta de entrada para a participação nas práticas de literacia/ letramento de uma comunidade social que faça uso de um determinado código escrito.

\section{Conhecimento da competência linguística e da literacia emergente}

A competência linguística - o conhecimento que o falante possui sobre a língua da sua comunidade e que utiliza para a construção dos textos orais e escritos - é, naturalmente, determinante na alfabetização, pelo que se constitui como um dos focos do PCK para este processo. O professor deverá ter consciência de que o homem não nasce pré-programado para aprender a ler, mas nasce pré-programado para aprender a falar. Sabe-se hoje que a leitura usa (e alarga) as rotas neuronais da linguagem oral, daí que problemas ao nível da linguagem oral tenham repercussões na aprendizagem da leitura (DEHAENE, 2007), da mesma forma, aliás, que se registam benefícios para a linguagem 
oral decorrentes da aprendizagem da linguagem escrita. Sendo esta última um simbolismo de segundo grau, condicionado pelo simbolismo de primeiro grau que o precede e condiciona - a linguagem oral (DELACROIX, 1930) o professor alfabetizador precisa conhecer a natureza da linguagem, enquanto capacidade, e da língua, enquanto manifestação dessa mesma capacidade, bem como do processo do seu desenvolvimento, de modo a poder compreender que a língua nativa (L1) ainda está naturalmente em desenvolvimento no momento em que uma criança inicia o processo de alfabetização. Assumimos, assim, com Cagliari $(1998$, p. 2) que "sem o conhecimento competente da realidade linguística compreendida no processo de alfabetização, é impossível qualquer didática, metodologia ou solução de outra ordem”.

É este conhecimento, por parte do professor alfabetizador, que lhe permitirá entender que está em decurso um desenvolvimento numa das áreas centrais implicadas na leitura (a constituída pelo conhecimento lexical e sintático) e que poderá ainda estar a decorrer numa outra dimensão linguística crucial para o processo de alfabetização, como é a fonológica. Para que estejam plenamente habilitadas a identificar sons e sílabas a partir de letras e da forma como estas se organizam em estruturas silábicas, bem como as respetivas unidades suprassegmentais, é também importante ter em consideração que as crianças, no seu processo de aquisição linguística, deparam-se com situações conflituosas, face às quais devem ser ajudadas pelo professor, com base no conhecimento das propriedades linguísticas relevantes, quanto às relaçôes entre a fala e a escrita. Tal conhecimento passa por conteúdos de natureza linguística, sejam as relaçóes fonema/grafema que regem o nosso sistema de escrita alfabético, as convençôes ortográficas, bem como as práticas sociais e usos da língua escrita, entre outros.

Atendendo ao caráter arbitrário da linguagem e ao facto de a linguagem escrita ser um produto cultural resultante de convençóes que não são descobertas naturalmente pelas crianças, torna-se indispensável que, no processo de alfabetizaçáo, estes aspectos também sejam enfatizados e refletidos, de modo que as crianças possam (re)construir concepçóes de leitura e escrita coerentes com a natureza desse produto cultural. Nesse sentido, ganham particular relevância as atividades que têm por objetivo desenvolver a literacia emergente, na sequência do que autores como Clay (1972), Ferreiro e Teberosky (1986) ou Teale e Sulzby (1992) têm defendido: quanto mais claras e próximas da realidade forem as ideias que as crianças pré-leitoras constroem sobre a natureza 
e funções da linguagem escrita, tanto mais facilitada será a aprendizagem da leitura. De facto, nas últimas duas décadas do universo educativo português, tem vindo a implementar-se uma dinâmica sócio-construtivista no entendimento do processo de descoberta e apropriação da linguagem escrita (MATA, 2002, 2008), salientando-se não só o papel da criança ao longo desse processo, mas também o de todos aqueles que com ela contactam no seu quotidiano, quer em ambientes formais, quer informais.

\section{Conhecimento curricular relevante para o processo de alfabetização}

Em Portugal, o currículo oficial, sobretudo o Programa de Português para Ensino Básico (PPEB), em vigor desde 2011/2012, complementado pelas Metas Curriculares de Português (MCP) para o $1^{\circ}$ Ciclo do Ensino Básico, em vigor desde 2012/2013, e também das Orientaçōes Curriculares para a Educação Pré-Escolar (OCEPE) (PORTUGAL, 1997), complementadas pelas respectivas Metas de Aprendizagem (PORTUGAL, 2010), bem como todos os documentos de suporte que têm vindo a ser produzidos ao abrigo destes, legitimam a complexidade de conhecimentos acima enunciados porquanto eles estáo, de uma forma ou de outra, refletidos nesses mesmos documentos ${ }^{6}$.

Centrando-nos, em particular, no enquadramento curricular para o $1{ }^{\circ}$ Ciclo do Ensino Básico, deparamo-nos com a necessidade, por parte dos docentes desta valência, de promover a articulaçáo entre dois documentos orientadores que coexistem - de uma forma que, por vezes, gera dificuldades de articulação (SILVA, 2015): o PPEB e as MCP. Por um lado, no PPEB explicitam-se alguns conteúdos não retomados nas $\mathrm{MCP}$, como sejam as funçóes da leitura, a importância de ativar quer a via direta quer a via indireta no processo de identificação das palavras escritas, as questóes relativas às funçóes e estratégias de leitura, entre outras. Já as MCP para o $1^{\circ}$ Ciclo explicitam, de forma clara e sintética, o trabalho a ser proporcionado pelo professor alfabetizador, quer em torno do desenvolvimento da consciência fonológica (ao nível da discriminação de pares mínimos, da contagem silábica de palavras com distintas extensóes e constituiçôes silábicas, da manipulação silábica e fonémica), quer ainda do treino da velocidade e precisão na leitura de palavras e pseudopalavras. A monitorizaçáo da compreensáo da leitura, bem como a necessidade de contemplar atividades de leitura em diferentes tipologias são 
igualmente previstas. As orientações das MCP são complementadas por um caderno de apoio intitulado Aprendizagem da leitura e da escrita, no qual, para além da evocação dos fundamentos teóricos e da explicitação da motivação subjacente aos descritores de desempenho assinalados, sáo oferecidas sugestóes para a avaliaçâo (i.e. verificação do seu cumprimento por parte do aluno). Esses recursos, a par de um conjunto de materiais produzidos no âmbito da formação do Programa Nacional de Ensino do Português (PNEP) - conferir, nomeadamente, Sim-Sim $(2007,2009)$, Viana (2007), Freitas, Alves e Costa (2007), Duarte (2008), Pereira (2010) - constituem-se como documentos reguladores do trabalho dos professores do $1^{\circ}$ Ciclo, tornando assim acessível, pela linguagem adotada e através da ilustração de atividades disponibilizadas, os principais referenciais teóricos na área.

Cremos que o desafio da apropriaçáo desses referenciais curriculares para a prática docente reside justamente no conhecimento do conteúdo sujeito a reflexão e à busca de sentido entre a teoria e a prática. É este conhecimento do conteúdo que, para além de ajudar o professor a perceber o racional que fundamenta distintas premissas e orientaçóes curriculares, lhe permitirá ir para além de uma leitura rígida e simplista dos mesmos.

\section{Conhecimento dos princípios pedagógicos da aprendizagem da literacia e das estratégias de alfabetização}

As teorias pedagógicas de base socioconstrutivista têm destacado a centralidade de três princípios gerais da pedagogia literacia (THE NEW LONDON GROUP, 2000): prática situada (aprender literacia em contextos sociais autênticos de utilizaçáo significativa da linguagem escrita); ensino explícito dos conhecimentos culturais e procedimentos necessários à construção de significado com a linguagem escrita; e prática situada transformada de construção de significado com os conhecimentos, entretanto, aprendidos.

A pedagogia da alfabetização não pode passar à margem desses preceitos pedagógicos fundamentais de aprendizagem da literacia. A pedagogia específica da alfabetização obedece a esses princípios quando o professor, tendo em consideraçáo os conhecimentos prévios e os curriculares relevantes, desenha práticas de literacia que sejam situações de aprendizagem suficientemente significativas para que as crianças possam participar ativamente na construção dos significados veiculados pelos escritos, serem incitadas a pensar explicitamente sobre o que estão a fazer e a aprender, assim como a usar as novas aprendizagens 
(ainda) nessas ou noutras situações de literacia. Contudo, essa atividade não dispensa a necessidade de uso de estratégias pedagógicas específicas.

São de dois grandes tipos as metodologias tradicionais de alfabetização em Portugal: uma de base mais sintética, que parte da aprendizagem da letra para a sílaba, palavra e frase; e outra analítica, que percorre o caminho oposto. A escolha do método é, regra geral, dependente de preferências pessoais, da ajuda de professores mais experientes ou dos caminhos traçados adhoc pelos manuais escolares. Contudo, essas práticas ficam aquém do esperado, tendo em conta tudo o que aqui vimos sistematizando. Por exemplo, poderia pensar-se que nos métodos de base analítica o primeiro trabalho a ser efetuado seria o de análise, mais concretamente de análise da linguagem oral, o que raramente é feito. Parte-se, sim, da análise da palavra escrita (e não da palavra ouvida/ dita) e a análise é essencialmente gráfica e efetuada sobre frases ou palavras, descendo depois às sílabas, com as quais a criança partirá à descoberta de novas palavras. Nesses contextos, espera-se, por exemplo, que a criança adivinhe que <e> é lido como [i] (no início da palavra elefante) e que, no final deste longo processo, descubra que as sílabas são constituídas por fonemas. Quer dizer, a criança que é alfabetizada através de metodologias de base analítica pode passar um longo período de alfabetizaçáo sem ter percebido que a linguagem escrita se relaciona com a linguagem oral e pode ter desenvolvido a ideia de que a nossa escrita é silábica.

No caso dos métodos de base sintética, começa-se tradicionalmente pelas letras, porque os fonemas são difíceis de isolar (por serem coarticulados) e difíceis de ensinar. Também se justifica que se parta da letra para o som porque o nome de algumas letras contém alguns dos sons que representam (embora autores como Treiman e Tincoff (1997) considerem que aprender o nome das letras - dê, têe, pê...- foca a atenção na sílaba e não no fonema, bloqueando a compreensão conceptual do modo como o alfabeto funciona), ou porque as letras são concretas e visíveis e os sons abstratos (embora não esteja provado que as letras sejam mais concretas para as crianças do que os sons da sua própria fala). Mas as diferenças entre progredir instrucionalmente da letra para o som ou do som para a letra são substanciais: a lógica da letra para o som bloqueia a compreensão "de onde vem esse som" e a compreensão de que os sons são a base do código, o que é potenciado pela lógica som-letra. A escolha das estratégias de alfabetização não pode, por isso, ser apenas inspirada pela tradição. O que parece indiscutível é que: 
É difícil compreender que haja quem defenda que a aprendizagem da leitura náo necessita de ensino, argumentando que a criança, senhora de uma inteligência ativa, construtora de hipóteses, rapidamente descobre, sem ajuda do professor, qual é o elo que liga o alfabeto à fala. Na verdade, esse elo é altamente abstrato (MORAIS, 2012, p. 32-33).

Se, de facto, queremos ter professores alfabetizadores detentores de um conhecimento de base sólido, então a determinação do caminho pedagógico específico a seguir para realizar esse ensino tem de ultrapassar o atual quadro de conhecimento intuitivo e ter em atenção todas as variáveis de saber até agora consideradas. $\mathrm{O}$ aprendiz leitor tem de entender que vai aprender um código e que este código representa de forma gráfica as palavras que ele ouve e diz (MCGUINNESS, 2006), e também que se trata de um código essencial na sua própria vida social, independentemente do método de ensino do professor. Por outro lado, as operaçóes cognitivas em que se deve treinar o aprendente são tanto exigidas pelos métodos de base sintética como pelos métodos de base global (via sublexical, nos métodos de base sintética; via lexical, nos métodos globais), embora convocadas em momentos diferentes na progressão da aprendizagem, com os métodos analíticos a serem muito mais cautelosos no que concerne à prática situada e às competências prévias de literacia emergente (DIAS; CRISTIN, 1980) e de consciência de palavra, e os sintéticos supostamente muito mais exigentes do que os analíticos nas capacidades de consciência fonológica e no ensino explícito. Emerge aqui uma competência linguística fundamental no processo de alfabetização, que é a consciência linguística, que merece consideração em função dos resultados das investigaçóes que têm sido desenvolvidas.

A consciência linguística é um conhecimento linguístico que se situa na transição entre aquilo que podemos considerar o conhecimento linguístico implícito que a criança traz à entrada no $1^{\circ}$ Ciclo do Ensino Básico e o conhecimento explícito (gramatical) da língua, que terá oportunidade de explorar de forma sistematizada e refletida a partir deste ciclo de escolaridade. A consciência linguística, contrariamente ao conhecimento implícito da língua, necessita ser estimulada durante o processo de alfabetizaçáo, dado que, nas suas dimensões mais importantes, não emerge espontaneamente. Tratase nomeadamente da consciência fonológica (em particular da consciência 
fonémica), da palavra e da frase (FREITAS; ALVES; COSTA, 2007; DUARTE, 2008). Por outro lado, sendo considerada como uma competência preditora de futuros desempenhos positivos em termos da leitura, ela beneficia igualmente da própria aprendizagem da leitura, naquilo que poderíamos considerar um círculo virtuoso.

A formação de professores necessita, pois, de investigação que analise práticas de fundamentadas por todos estes conjuntos de saberes específicos de modo a completar o PCK da alfabetização.

\section{Conhecimento do contexto: famílias e comunidade (escolar e não escolar)}

O conhecimento do contexto (escola, comunidade, famílias) tem inúmeras dimensôes (por exemplo, logísticas, administrativas, afetivas) que condicionam o trabalho do alfabetizador, mas neste texto apenas daremos ênfase àqueles aspectos diretamente relevantes na construçáo da pedagogia específica da alfabetização.

O conhecimento das famílias e da comunidade ganha particular interesse na medida em que esses âmbitos de vida dos aprendentes podem potenciar a alfabetização que acontece em sala de aula. As práticas de literacia das famílias são um dos âmbitos de construção da literacia emergente das crianças e elas são, também, pela mesma ordem de razões, uma extensão da aprendizagem formal que acontece no âmbito pedagógico. É por isso muito relevante que o alfabetizador conheça esse contexto, de modo a assim programar atividades em cooperação com as famílias (ou que desafiem essas práticas) que façam pontes com as aprendizagens escolares das crianças. Desse modo, as crianças podem reforçar e validar as aprendizagens que constroem com o professor alfabetizador, mobilizando-as para, gradualmente, renovar a sua participação nas práticas de literacia familiares.

A relevância do conhecimento da comunidade escolar e além-escolar para o professor alfabetizador sustenta-se em razóes semelhantes, já que a comunidade, de que, aliás, a família também faz parte, é o âmbito autêntico da prática da literacia que se aprende na escola: é a sua razão de ser. Comunicar por escrito com a direçâo do centro ou com uma empresa que vai fazer um serviço de transporte escolar das crianças, ou sair para a comunidade à procura da literacia, mobilizando e validando os conhecimentos aprendidos e procurando novos 
desafios, decorrem de um conhecimento contextual do professor alfabetizador, que justamente coloca esse conhecimento ao serviço da construção do seu PCK. O conhecimento das famílias e da comunidade torna-se, assim, relevante na construção, pelo alfabetizador, de práticas de literacia transformadas para os estudantes que estâo a ser alfabetizados.

\section{Considerações finais}

Neste texto, o quadro teórico de Shulman $(1986,1987)$ é explorado à procura da resposta à seguinte questáo: Qual o conhecimento de base do professor alfabetizador?

A discussão realizada permitiu-nos identificar duas grandes dimensôes estruturadoras da resposta a essa questão. Uma parte da resposta diz respeito à categorizaçáo desse conhecimento de base, e uma outra às limitaçóes que identificámos no processo dessa categorização.

A sistematização do conhecimento de base do professor alfabetizador que propomos integra entendimentos de diferentes origens, estruturando-se em torno do conhecimento específico da leitura, do socioconstrutivismo, do conhecimento do contexto e de um PCK específico, constituído por uma formulação clara das finalidades da alfabetizaçáo, um conhecimento de competências linguísticas e literácitas dos aprendentes, das informações curriculares, de conhecimentos didáticos relevantes para o processo da alfabetizaçáo. $\mathrm{O}$ modelo que oferecemos coloca em destaque o $\mathrm{PCK}$, náo o desgarrando, tal como no modelo que the serve de base, dos restantes domínios de conhecimento implicados. O modelo configura o que, em nosso entender, não pode deixar de ser ensinado ao professor alfabetizador.

A explicitação deste modelo contribui para explicar a complexidade inerente à formação do alfabetizador. Parece-nos que o atual contexto português de formaçáo de professores de $1^{\circ}$ Ciclo apresenta potencialidades para a construção deste perfil de professor, em função do tempo que, por lei, lhe é destinado. É, aliás, nossa convicçáo que a complexidade detectada no modelo proposto justificaria a existência de uma unidade curricular exclusiva para essa formação específica e uma atenção séria à experimentação prática desta tarefa docente. Em nosso entender, o modelo que oferecemos contribui também para a compreensão das dificuldades sentidas pelos jovens professores no momento de assumir o papel de alfabetizadores. 
Além disso, a explicitação do modelo também coloca em destaque algumas limitaçóes sérias do mesmo, tornando, desse modo, ainda mais evidentes as razóes para essas mesmas dificuldades. Com efeito, há uma categoria de conhecimentos fundamentais no núcleo do PCK que permanece subinvestigada, nomeadamente a constituída pelo conhecimento das estratégias de alfabetização, em relação com o conhecimento dos princípios pedagógicos do ensino da literacia e com os demais conhecimentos estruturadores de PCK. Esta é a segunda dimensão que estrutura a nossa resposta à pergunta que orienta este texto.

Como acima afirmámos, o PCK é em boa medida construído na prática em função do contexto em que decorre a prática. Em nosso entender, atualmente o acesso ao conhecimento das estratégias de alfabetização, por parte dos professores, depende sobremaneira das heranças "tradicionais" (i.e. não sistematizadas, intuitivas) de práticas alfabetizadoras de professores mais experientes. Dito de outro modo, este conhecimento docente náo tem sido investigado.

Contudo, os professores em formação precisam que esse trabalho seja de alguma forma preparado/mostrado/ilustrado com investigação, concretizando assim o modo como todo o restante conhecimento de referência investigativa se integra e se pode mobilizar na alfabetização. Mostrando a importância e a exequibilidade da simbiose das ideias teóricas e das práticas tradicionais e apesar de não ser uma panaceia, tal trabalho investigativo, oferecido ao professor alfabetizador na forma de casos (SHULMAN, 1986, 1987), seria "a means for developing strategic understanding, for extending capacities toward professional judgment and decision making" (SHULMAN, 1986, p. 12), contribuindo assim para tornar o período formativo num maior encontro com a prática esperada, que, pelo menos para já, permanece meramente "idealizada". Em nosso entender, tal contribuiria para que os professores deixassem de ter receio de assumir o papel de alfabetizadores.

Contudo, este trabalho investigativo não está feito e, por isso mesmo, não se pode ensinar e aprender solidamente no ensino superior. É nossa convicção que, nas atuais condiçóes de formação, a construção desses casos formativos poderá ser realizada pelos próprios alunos durante as suas práticas de estágio, que seguem o modelo de investigação-ação (FLORES; VIEIRA; FERREIRA, 2014). Os relatórios de estágio, que são defendidos em provas públicas e tornados acessíveis através dos repositórios das instituições de formação, configuram-se como espaços de desenvolvimento e de disseminaçáo dessas 
investigações. Além disso, essa pesquisa também pode ser alimentada pelos processos de formação contínua (PEREIRA, 2010) e pelo estudo académico de práticas em sala de aula de professores alfabetizadores hábeis e experientes.

Esta limitação não parece ser exclusiva da área da alfabetização. Segundo Fernandez (2011, p. 8), "As pesquisas de PCK estão iniciando e ainda há relativamente pouco material que contribua efetivamente para a formação de professores", muito embora haja áreas em que esse trabalho tem avançado de um modo muito inspirador (conferir o trabalho de Deborah Ball e colaboradores (BALL, 1990; BALL; THAMES; PHELPS, 2008; HILL; BALL; SCHILLING, 2008). A reflexão que realizámos durante a construção deste artigo motivou definitivamente o nosso interesse pela pesquisa do conhecimento de base do professor alfabetizador.

\section{Notas}

1 "O exercício de um julgamento fundamentado em detrimento da manifestaçáo de um comportamento correto" (Tradução nossa).

2 "A visão que defendo do ensino e da formação de professores é uma visão de profissionais que são não apenas capazes de agir, mas, essencialmente, de legitimar - de agir de uma forma autoconsciente relativamente àquilo que os seus atos representam ou implicam” (Tradução nossa).

3 "O mero conhecimento do conteúdo é, provavelmente, tão inútil pedagogicamente, quanto uma competência desprovida de conteúdo" (Tradução nossa).

4 "Entre estas categorias, o conhecimento didático do conteúdo adquire particular interesse porque identifica os corpora de conhecimento distintivos para o ensino. Representa a fusão entre conteúdo e pedagogia, através da qual se alcança a compreensão de como determinados temas, problemas ou questóes se organizam, se representam e se adaptam aos diversos interesses e capacidades dos alunos e, também, como são expostos para o seu ensino" (Tradução nossa).

5 "A compreensão por si só não é suficiente. A utilidade de tal conhecimento reside no seu valor para o julgamento e para a ação" (Tradução nossa).

${ }^{6}$ Posteriormente à aceitação desde texto foi, por despacho n. ${ }^{\circ}$ 2109/2015 do Ministério da Educaçáo e Ciência, revogado o Programa de Português 
para o Ensino Básico que havia sido homologado em março de 2009, entrando em vigor, já no ano letivo de 2015/2016, o novo Programa e Metas Curriculares de Português, o qual substitui os documentos anteriores. Entretanto, as Metas de Aprendizagem para a Educação PréEscolar deixaram de estar acessíveis no sítio do Ministério da Educação e as OCEPE estão a ser alvo de uma reformulação, indícios da atenção que estấo a receber por parte da tutela.

7 “[...] uma forma de desenvolver uma compreensão estratégica de reforçar capacidades visando o discernimento e a tomada de decisão profissional" (Tradução nossa).

\section{REFERÊNCIAS}

BALL, Deborah L. The mathematical understandings that prospective teachers bring to teacher education. Elementary School Journal, Chicago, v. 90, n. 4, p. 449-466, mar. 1990.

BALL, Deborah L., THAMES, Mark Hoover, \& PHELPS, Geoffrey. Content knowledge for teaching: What makes it special? Journal of Teacher Education, 59(5), 389-407, 2008.

BALOTA, David. The role of meaning in word recognition. In: Balota, David; Flores, Giuseppe D’Arcais; Rayner, Keith (Ed.). Comprehension processes in reading. London: Routledge, 1990. p. 9-32.

BRUNER, Jerome. Realidad mental y mundos posibles: los actos de la imaginación que dan sentido a la experiencia. Barcelona: Gedisa, 1988.

CAGLIARI, Luiz Carlos. Alfabetizando sem o bá-bé-bi-bó-bu. São Paulo: Scipione, 1998.

CLAY, Marie. Reading. The Patterning of complex Behaviour. Exeter, NH: Heinemann Educational Books, 1972.

COLHEART, Max et al.. Models of reading aloud: dual-route and paralleldistributed processing approaches. Psychological review, n. 100, p. 589-608, 1993.

DEHAENE, Stanislas. Les neurones de la lecture. Paris: Odile Jacob, 2007. 
DELACROIX, Henri. Le langage et la pensée. 2. ed. Paris: Alcair, 1930.

DIAS, Bosco; CRISTIN, Fabienne. Principes psychologiques sous-jacents à la progression de l'apprentissage de la lecture dans les méthodes analytiques et synthétiques. Réeducation Orthophonique, n. 114, p. 351-364, 1980.

DONALDSON, Margaret. Children's minds. London: Fontana, 1984.

DUARTE, Inês. O conhecimento da língua: desenvolver a consiência linguística. Lisboa: MEC, 2008.

EHRI, Linea. Reconceptualizing the development of sight word reading and its relationship to recording. In: GOUGH, Philip; EHRI, Linea; TREIMAN, Rebecca (Ed.), Reading acquisition. Hillsdale: Lawrence Erlbaum Associates, 1992. p. 107-143.

FERNANDEZ, Carmen. PCK - Conhecimento Pedagógico do Conteúdo: perspectivas e possibilidades para a formação de professores. In: ENCONTRO NACIONAL DE PESQUISA EM EDUCAÇÃO E CIÊNCIAS, 8., 2011, Campinas. Anais... Campinas, SP: ABRAPEC, 2011. Disponível em: <http://www.nutes.ufrj.br/abrapec/viiienpec/resumos/r03701.pdf>. Acesso em: 15 ago. 2014.

FERREIRO, Emília; TEBEROSKY, Ana. Psicogênese da lingua escrita. Porto Alegre: Artes Médicas, 1986.

FLORES, Assunção; VIEIRA, Flávia; FERREIRA, Fernando. Formação inicial de professores em Portugal: problemas, desafios e o lugar da prática nos Mestrados em Ensino Pós-Bolonha. In: BORGES, Maria Célia;

AQUINO, Orlando Fernandez (Org.), A formaçâo inicial de professores: uma visão internacional. Uberlândia, MG: EDUFU, 2014, p. 61-96.

FREITAS, Maria João; ALVES, Dina; COSTA, Teresa. O conhecimento da lingua: desenvolver a consciência fonológica. Lisboa: MEC, 2007.

GIASSON, Jocelyne. La lecture: de la théorie à la pratique. Bruxelles: De Boeck, 2005.

GROSSMAN, Pamela. The making of a teacher: teacher knowledge and teacher education. New York: Teachers College Press, 1990. 
HILL, Heather C.; BALL, Debora L.; SCHILLING, Stephen G. Unpacking pedagogical content knowledge: conceptualizing and measuring teachers' topic specific knowledge of students. Journal for Research in Mathematics Education, v. 39, n. 4, p. 372-400, 2008.

IRWIN, Judith W. Teaching reading comprehension processes. 3. ed. Boston, MA: Allyn and Bacon, 2007.

MAGNUSSON, Shirley; KRAJCIK, Joseph; BORKO, Hilda. Nature, sources, and development of pedagogical content knowledge for science teaching. In: GUESS-NEWSOME, Julie; LEDERMAN, Norman G. (Org.). Examining pedagogical content knowledge: the construct and its implications for science education. Dordrecht: Kluwer Academic Publishers, 1999. p. 95-132.

MATA, Lourdes. Literacia Familiar: caracterização de práticas de literacia em famílias com crianças em idade pré-escolar e estudo das suas relaçôes com as realizaçóes das crianças. 2002. Tese (Doutoramento em Estudos da Criança) - Universidade do Minho, 2002.

MATA, Lourdes. A descoberta da escrita. Lisboa: Direção-Geral de Inovação e Desenvolvimento Curricular, 2008.

MCGUINNESS, Diana. O ensino da leitura: o que a ciência nos diz sobre como ensinar a ler. Porto Alegre: Artmed, 2006.

MORAIS, José. Criar leitores. O ensino da leitura: para professores e encarregados de educação. Porto: Livpsic, 2012.

NÓVOA, António. Profissão Professor. 2. ed. Porto: Porto Editora, 1995.

ONG, Walter, Orality and Literacy: the technologizing of the word. 2. ed. New York: Routledge, 2002.

PEREIRA, Íris Susana Pires (Ed.). O ensino do português no $1^{\circ}$ ciclo do ensino básico: construção de saberes profissionais no contexto do PNEP e do novo programa de português. Braga: Universidade do Minho, 2010. 2 v.

PEREIRA, Íris Susana Pires. Para um entendimento da complexidade da aprendizagem da leitura. In VIANA, Fernanda Leopoldina; RIBEIRO, Iolanda; BAPTISTA, Adriana (Ed.). Ler para ser: os caminhos antes, durante e... depois de aprender a ler. Coimbra: Almedina, 2014. p. 93-119 
PORTUGAL. Ministério da Educação. Orientaçôes curriculares para a Educação Pré-Escolar, Lisboa: Ministério da Educação; Departamento da Educação Básica; Núcleo de Educação Pré-Escolar, 1997.

PORTUGAL. Ministério da Educação (Coord. de I. Sim Sim). Metas de Aprendizagem, Lisboa: Ministério da Educação, 2010.

PORTUGAL. Decreto-lei no 240/2001, de 30 de agosto de 2001. Aprova o perfil geral de desempenho profissional do educador de infância e dos professores dos ensinos básico e secundário. Diário da República, Lisboa, 30 ago. 2001a.

PORTUGAL. Decreto-lei no 241/2001. 30 de agosto de 2001. Aprova o perfil específico de desempenho profissional do educador de infância e dos professores dos ensinos básico e secundário. Diário da República, Lisboa, 30 ago. 2001b.

PORTUGAL. Decreto-lei no 43/2007, 38 de 22 de fevereiro de 2007. Regime Jurídico de Habilitação para a Docência. Diário da República, Lisboa, 22 fev. 2007.PORTUGAL. Decreto-lei no 79/2014, 14 de maio de 2014. Regime Jurídico de Habilitação para a Docência. Diário da República, Lisboa, 14 maio 2014.

RAMOS, Valmor; GRAÇA, Amândio B. S.; NASCIMENTO, Juarez V. O conhecimento pedagógico do conteúdo: estrutura e implicaçóes à formação em educação física. Revista Brasileira de Educação Física e Esporte, São Paulo, v. 22, n. 2, p. 161-71, abr./jun. 2008.

RAND. Reading Study Group. Reading for understanding: Toward an R\&D program in reading comprehension. Santa Monica, CA: RAND Corporation, 2002.

SALLES, Jerusa Fumagalli; PARENTE, Maria Alice Mattos Pimenta. Processos cognitivos na leitura de palavras em crianças: relaçóes com compreensão e tempo de leitura. Psicologia: Reflexão e Crítica, Porto Alegre, v. 12, n. 1, p. 321-331, 2002.

SALLES, Jerusa Fumagalli; PARENTE, Maria Alice Mattos Pimenta. Compreensão textual em alunos de segunda e terceira séries: uma abordagem cognitiva. Estudos de Psicologia, Natal, v. 9, n. 1, p. 71-80, jan./abr. 2004. 
SCHÖN, Donald. The reflective practitioner: how professionals think in action. New York: Basic books, 1983

SHULMAN, Lee $S$. Those who understand: knowledge growth in teaching. Educational Researcher, v. 15, n. 4, p. 4-14, 1986.

SHULMAN, Lee $S$. Knowledge and teaching: foundations of a new reform. Harvard Educational Review, v. 57, n. 1, p. 1-22, 1987.

SILVA, Cristina V. De Programa em Programa até às Metas Curriculares de Português: o desenho de percursos de aprendizagem na educação linguística. In Ferreira, A.M. \& Brasete, M. F. (Eds.), Pelos Mares da língua portuguesa 2. Aveiro: UA Editora, p. 283-294, 2015.

SIM-SIM, Inês. Um retrato da situação: os dados e os factos. Cadernos da Formação de Professores, Lisboa, n. 2, p. 51-61, 2001.

SIM-SIM, Inês. O Ensino da Leitura: a compreensão de textos. Lisboa: Ministério da Educação, 2007.

SIM-SIM, Inês. O Ensino da Leitura: a decifração, Lisboa: Ministério da Educação, 2009.

TARDIF, Maurice. Saberes docentes e formação profissional. Petrópolis, Vozes. 2002.

TEALE, William; SULZBY, Elizabeth. Emergent Literacy: writing and reading. Norwood: Ablex, 1992.

THE NEW LONDON GROUP. A pedagogy of multiliteracies. In: COPE, Bill; KALANTZIS, Mary (Ed.). Multiliteracies. London: Routledge, 2000. p. 19-37.

TREIMAN, Rebecca; TINCOFF, Ruth. The fragility of the alphabetic principle: children's knowledge of letter names can cause them to spell syllabic rather than alphabetically. Journal of Experimental Child Psychology, n. 64, p. 425-451, 1997.

VIANA, Fernanda Leopoldina. Do aprender a ler ao gostar de ler. Um caminho a descobrir. In Atas do Seminário Educação e Leitura, p. 13-20, 2006. Disponível em: <http://hdl.handle.net/1822/11786>. Acesso em: 15 ago. 2014. 

de base do professor alfabetizador

VIANA, Fernanda Leopoldina. O Ensino da Leitura: a avaliação. Lisboa: Direção-Geral de Inovação e Desenvolvimento Curricular, 2007.

VYGOTSKY, Lev S. Pensamiento y lenguaje. Barcelona: Paidós, 1995.

WEISZ; Telma. O diálogo entre o ensino e a aprendizagem. São Paulo: Ática, 2002.

YUILL, Nicola; OAKHILL, Jane. Children's problems in text comprehension: an experimental investigation. Cambridge, MA: Cambridge University Press, 1991. 


\section{Sobre la formación del maestro de la educación primaria: una contribución para la caracterización del conocimiento de base del maestro alfabetizador}

\section{Resumen}

En este trabajo recuperamos el marco teórico propuesto por Lee S. Shulman para dar respuesta a la siguiente cuestión: ¿Cuál es el conocimiento de base de un profesor alfabetizador? Nuestra respuesta es que la enseñanza de la alfabetización implica convocar y operacionalizar conocimientos de diferente naturaleza, algunos de los cuales muy poco investigados y, por esta razón, todavía muy dependientes de intuiciones y prácticas no sistematizadas, difícilmente susceptibles de ser aprendidas en los contextos de formación académica. Argumentamos que es por este mismo tipo de razones que la tarea pedagógica de enseñar a leer resulta difícil de imaginar para los jóvenes profesores. Defendemos que el modelo de conocimiento del profesor alfabetizador que aquí presentamos se configura como básico en la concepción de la formación de tal profesor en el actual contexto formativo en Portugal, que también será brevemente caracterizado.

Palabras claves: Profesor alfabetizador. Aprendizaje profesional. Maestro de educación primaria.
On early literacy teacher education: a contribution for characterizing the knowledge base for the early literacy teacher

\begin{abstract}
In this paper, we recover the theoretical framework proposed by Lee S. Shulman to answer to the following question: What is the base knowledge of the literacy teacher? From this question, one may understand that the teaching of literacy implies in the calling and in the operationalization of different kinds of knowledge, some of which have not been researched deeply and, for this reason are still dependent on intuition and unsystematic practices that are hardly available for learning in academic contexts training. We argue that it is for this same reason that the pedagogical task of teaching to read becomes difficult to be conceived by young teachers. We sustain that the model of knowledge of the literacy teacher that we present can be considered in the design of the current Portuguese literacy teacher training context, which we is also characterized briefly.
\end{abstract}

Keywords: Early Literacy Teacher. Professional Learning. Elementary School Teacher. 
Íris Susana Pires Pereira

E-mail: iris@ie.uminho.pt

Fernanda Leopoldina Viana

E-mail: fviana@ie.uminho.pt

Cristina Vieira da Silva

E-mail: cristina.vieira@esepf.pt

Enviado em: $30 / 8 / 2014$

Aprovado em: 26/11/2014 